\title{
Modified Extravesical Ureteroneocystostomy in Cadaveric Kidney Transplantation with Completely Duplicated Ureters: A Case Report
}

\section{Birkan Bozkurt ${ }^{1^{\star}}$, Mehmet Tokaç ${ }^{1}$, Ersin Gürkan Dumlu' ${ }^{1}$, Özlem Yarar ${ }^{1}$ and Mehmet Kılıç ${ }^{2}$}

${ }^{1}$ Ankara Atatürk Education and Research Hospital, Center for Organ Transplantation, Ankara, Turkey

${ }^{2}$ Department of General Surgery, Yıldırım Beyazıt University School of Medicine, Ankara, Turkey

"Corresponding author: Birkan Bozkurt, Atatürk Training and Research Hospital, Organ Transplantation Center, Bilkent, Ankara, Turkey, Tel: +90312 291 2525/4510; Fax: +90 312291 2718; E-mail: birkan.bozkurt@gmail.com

Rec date: Mar 18, 2014, Acc date: May 18, 2014, Pub date: May 20, 2014

Copyright: ( 2014 Bozkurt B. This is an open-access article distributed under the terms of the Creative Commons Attribution License, which permits unrestricted use, distribution, and reproduction in any medium, provided the original author and source are credited.

\begin{abstract}
Completely duplicated ureters are not commonly used in renal transplantation due to increased risk of postoperative complications, such as urinary tract infections, stricture, reflux and urinary leakage. Although recent results have indicated that the occurrence of these complications is similar to that of a single ureter, few reports exist of renal transplantations of kidneys with ureteral duplication. Here, we report successful renal transplantation of a cadaveric kidney with completely duplicated ureters to a 52-year-old final stage renal disease patient who had been on dialysis for 19 years. A modified extravesical ureteroneocystostomy technique was employed, in which distal ureteric ends were spatulated and their medial edges were approximated. Double-j stent catheters were inserted during the ureteroneocystostomy and removed after 21 days when progressive serum creatine levels had decreased. During 6 months following the operation so far, no urinary tract infections, hydronephrosis, pyelonephritis, stricture, or reflux was reported. We conclude that modified extravesical ureteroneocystostomy, a newly described technique is suitable for the transplantation of a cadaveric kidney with complete ureteral duplication.
\end{abstract}

Keywords: Duplicated ureters; Kidney transplantation; Modified extravesical ureteroneocystostomy

\section{Introduction}

Ureteral duplication, where two ureters drain a single kidney, is the most common renal abnormality. The condition is not problematic as long as both ureters enter orthotopically or if the duplication is incomplete $[1,2]$. A kidney with duplicated ureters is more susceptible to post-operative urinary tract infections, stricture, reflux and urinary leakage; therefore, it is not a preferred option in kidney transplantations, in which postsurgical complications are the predominant cause of morbidity [3-5]. However, recent studies have revealed that the development of complications after transplantation of a donor kidney does not differ between completely duplicated ureters and a single ureter [5-7]. Given the increase in the number of hemodialysis patients over recent decades, and the shortage of renal allografts, development of a range of surgical techniques without postoperative complications is critical for the successful transplantation of a donor kidney with completely duplicated ureters $[2,7,8]$. Here, we present a technique of modified extravesical ureteroneocystostomy in which a cadaveric kidney with complete ureteral duplication was successfully transplanted to a final-stage renal disease recipient.

\section{Case Report}

The wait-listed recipient, a 52-year-old female, who had been on dialysis for 19 years due to final-stage renal disease from hypertensive nephropathy was called to the transplantation center for prospective cadaveric kidney donation. In the pre-operative evaluation, the human leukocyte antigen (HLA) mismatch number was found to be 2 and the lymphocyte cross match (LCM) was negative. Since there were no contraindications, the recipient underwent renal transplantation on October 11, 2013. In pre-operative back-table screening of the left kidney of the cadaveric donor, a single bilateral renal artery and a single vein, but double ureters with complete duplication were observed. Distal ureteric ends of the kidney with ureteral duplication were spatulated, and then their medial edges were approximated (Figure 1).
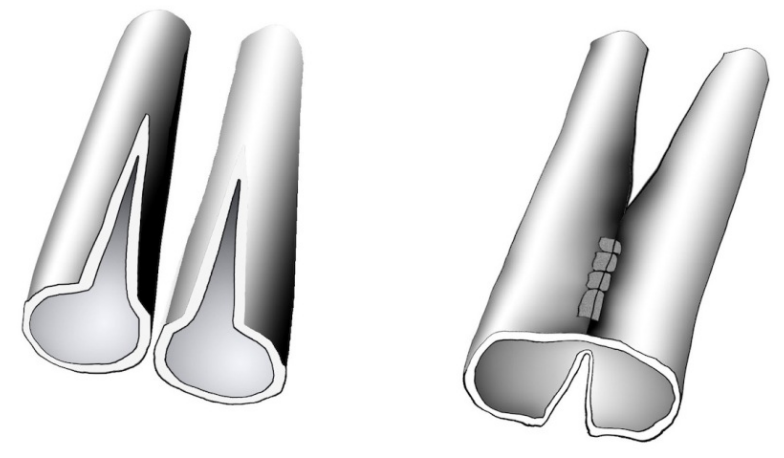

Figure 1: Modified extravesical method for ureterocystoneostomy, Duplicated ureters was sutured together from $1-\mathrm{cm}$ openings on the medial sides of the distal ends to form a single cuff.

The donor renal vein was anastomosed to the recipient external iliac vein and the donor renal artery to the recipient external iliac artery with $6 / 0$ prolen suture. Double-j stent catheters were inserted in 
Citation: Bozkurt B, Tokaç M, Dumlu EG, Yarar O, Kiliç M (2014) Modified Extravesical Ureteroneocystostomy in Cadaveric Kidney Transplantation with Completely Duplicated Ureters: A Case Report. J Transplant Technol Res 4: 131. doi:10.4172/2161-0991.1000131

Page 2 of 3

both lumens of single cuffed ureters during extravesical ureteroneocystostomy (Figures 2 and 3).

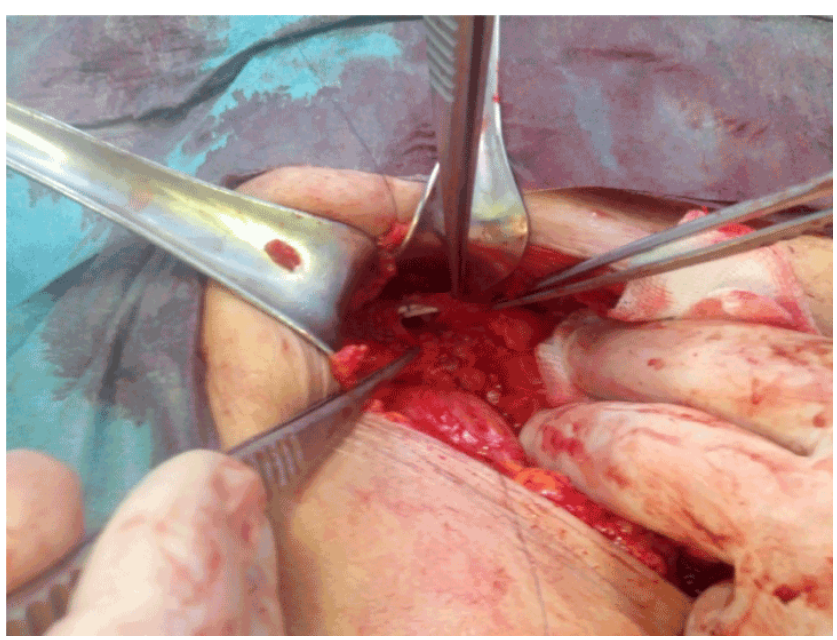

Figure 2: Double-j catheter in both lumens of the single-cuffed ureters.

Immunosuppression therapy included tacrolimus, mycophenolate mofetil (MMF) and steroids. There were no post-operative complications, but the recipient underwent dialysis twice for delayed graft function. The double-j stents were removed 21 days after the transplantation when progressive serum creatine levels had decreased (Figure 4).

The recipient was discharged 30 days after the transplantation with a serum creatine level of $1.1 \mathrm{mg} / \mathrm{dL}$ (normal range, $0.7-1.2 \mathrm{mg} / \mathrm{dL}$ ). The patient is currently under follow up for 6 months since transplantation. There were no urinary tract infections, hydronephrosis, pyelonephritis, stricture, or reflux so far during 6 months following transplantation.

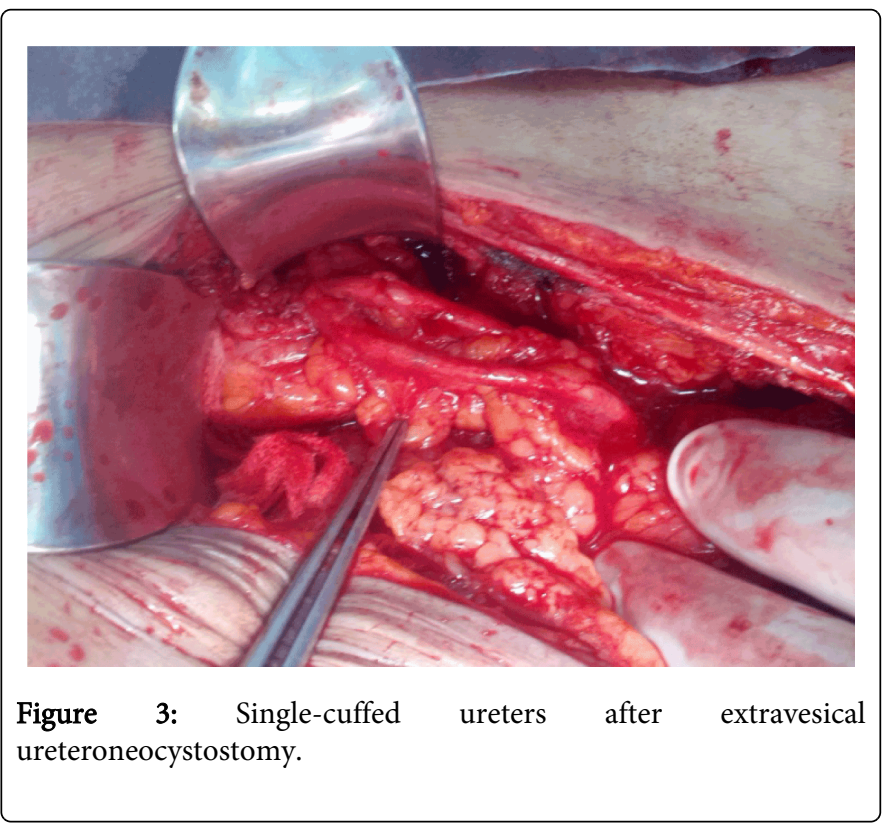

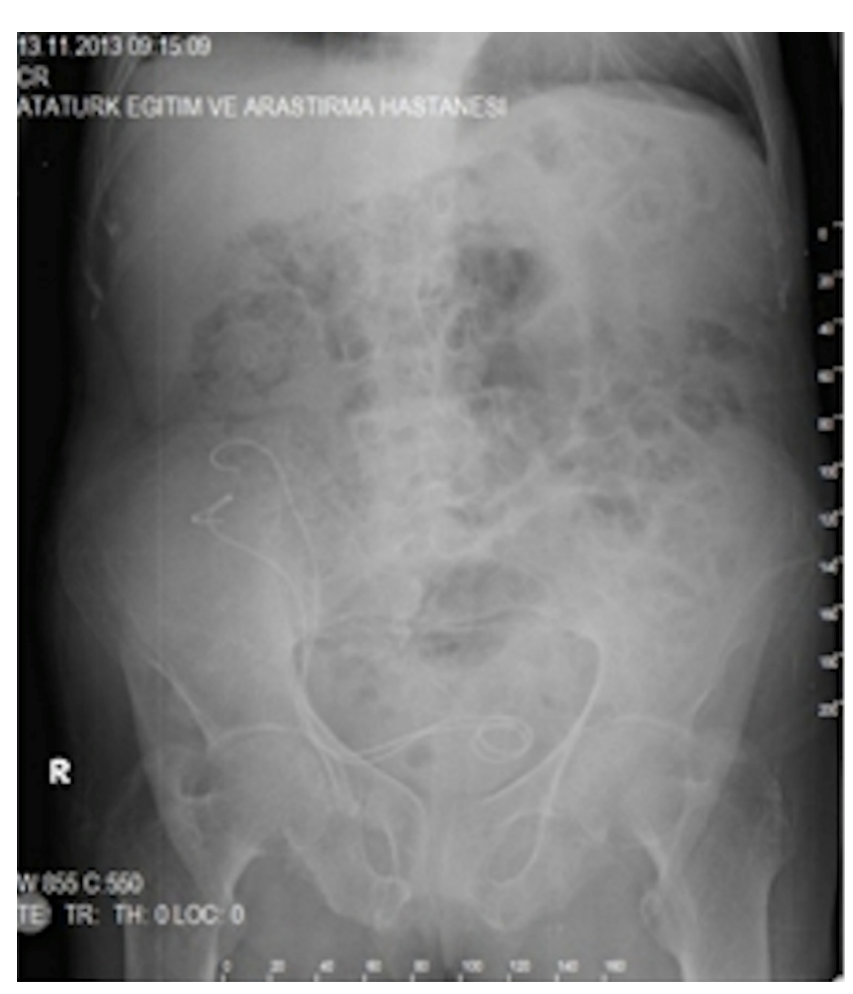

Figure 4: Recipient's post-transplant drip infusion pyelography showing two double-j stents before removal.

\section{Discussion}

Although complete ureteral duplication in the donor has previously been a contraindication for renal transplantation, recent renal transplantation cases with completely duplicated ureters have been reported as successful with respect to post-operative graft function $[5,9,10]$.

Intravesical and extravesical anastomosis are the most commonly used techniques for ureteroneocystostomy [11]. Extravesical ureteroneocystostomy is usually preferred because of its surgical simplicity and lower risks of post-operative urinary tract infections $[11,12]$. Completely duplicated ureters require several modifications to the extravesical ureteroneocystostomy. There are two primary approaches to re-implantation of duplicated ureters with the extravesical ureteroneocystostomy technique; both ureters can be separately anastomosed to the bladder [5], or a common ureteral ostium connected to the bladder can be formed between the distal parts of each ureter, known as ureteroureteral terminolateral anastomosis $[6,7,9]$.

Although ureteral duplication is the most common congenital malformation of the urinary tract, few cases in the literature describe kidney transplantations with completely duplicated ureters $[1-3,5,7,9,10]$. Here, we report a case study on cadaveric kidney transplantation from a completely duplicated ureter by modified extravesical ureteroneocystostomy where distal ureteric ends of duplicated ureters were spatulated and then their medial edges were approximated. The duplicated ureters anostomosed in distal part to form a single cuff were then sutured on the mucosa of the bladder. 
Citation: Bozkurt B, Tokaç M, Dumlu EG, Yarar O, Kiliç M (2014) Modified Extravesical Ureteroneocystostomy in Cadaveric Kidney Transplantation with Completely Duplicated Ureters: A Case Report. J Transplant Technol Res 4: 131. doi:10.4172/2161-0991.1000131

Page 3 of 3

This technique is different from the modified extravesical ureteroneocystostomy described in literature where both distal ends of the ureters were anastomosed to each other and then the modified Lich technique was used for ureteroneocystostomy [6]. Because the use of double-j stent catheters in extravesical ureteroneocystostomy, especially with narrow ureters, has been shown to be associated with a reduction in post-operative urological complications in renal transplantation [13], we inserted double-j stent catheters in both lumens of the single-cuffed ureters during the extravesical ureteroneocystostomy. Delayed graft function, which is common in renal transplantations from cadaveric donors, was the only postoperative complication. Six months have passed since the transplantation, and no postoperative complications such as urinary tract infections, hydronephrosis, pyelonephritis, stricture, or reflux was recorded during this period.

In conclusion, modified extravesical ureteroneocystostomy, which is a newly described technique, is appropriate for renal transplantations from cadaveric donor kidneys with complete ureteral duplication.

\section{References}

1. Uchida J, Naganuma T, Machida Y, Kitamoto K, Yamazaki T, et al. (2006) Modified extravesical ureteroneocystostomy for completely duplicated ureters in renal transplantation. Urol Int 77: 104-106.

2. Lee SS, Huh K (2013) Long-term result in ureteroneocystostomy for complete duplicated ureters in renal transplantation. J Korean Soc Transplant 27: 21-23.

3. Nakatani T, Uchida J, Kim T, Yamamoto K, Kishomoto T (2000) Modified extravesical ureterocystoneostomy of the kidney transplant allograft with completely duplicated ureters. Int J Urol 7: 313-315.
4. Nardo B, Montalti R, Pacile V, Bertelli R, Beltempo P, et al. (2006) The first case of ureteral duplication in a combined liver-kidney transplantation. Int J Artif Organs 29: 698-700.

5. Alberts VP, Minnee RC, van Donselaar-van der Pant KA, Bemelman FJ, Zondervan PJ, et al. (2013) Duplicated ureters and renal transplantation: a case-control study and review of the literature. Transplant Proc 45: 3239-3244.

6. Heidari M, Gharaati MR, Iran-Pour E, Simforoosh N, Zare S, et al. (2010) Transplantation of kidneys with duplicated ureters. Scand J Urol Nephrol 44: 337-340.

7. Lasaponara F, Dalmasso E, Bosio A, Pasquale G, Sedigh O, et al. (2013) Kidney transplant grafts with complete ureteral duplication. Exp Clin Transplant 11: 507-509.

8. Kakai F, Nikeghbalian S, Malekhosseini SA (2013) Kidney transplantation techniques. InTech 167.

9. Sulikowski T, Zietek Z, Ostrowski M, Kamiński M, Sieńko J, et al. (2005) Experiences in kidney transplantation with duplicated ureters. Transplant Proc 37: 2096-2099.

10. Sang SL, Kill H (2013) Long-term result in ureteroneocystostomy for complete duplicated ureters in renal transplantation. J Korean Soc Transplant 27: 21-23.

11. Slagt IK, Dor FJ, Tran TC, Kimenai HJ, Weimar W, et al. (2014) A randomized controlled trial comparing intravesical to extravesical ureteroneocystostomy in living donor kidney transplantation recipients. Kidney Int 85: 471-477.

12. Slagt IK, Klop KW, Ijzermans JN, Terkivatan T (2012) Intravesical versus extravesical ureteroneocystostomy in kidney transplantation: a systematic review and meta-analysis. Transplantation 94: 1179-1184.

13. Guleria S, Chahal R, Madaan S, Irving HC, Newstead CG, et al. (2005) Ureteric complications of renal transplantation: the impact of the double J stent and the anterior extravesical ureteroneocystostomy. Transplant Proc 37: 1054-1056. 